\title{
Produtividade de alface e qualidade de mudas de tomateiro com bioproduto de batata
}

\author{
Lettuce productivity and quality of tomato seedlings with potato bioproduct
}

\author{
Diogo Vanderlei Schwertner ${ }^{I^{*}}$ Alessandro Dal'Col Lúcio ${ }^{I}$ Daniel Santos ${ }^{I}$ \\ Fernando Machado Haesbaert ${ }^{\mathrm{I}}$ Rélia Rodrigues Brunes $^{\mathrm{I}}$
}

\section{RESUMO}

$O$ objetivo deste trabalho foi avaliar o efeito da aplicação de Acrescent Foliar ${ }^{\circledR}$, proveniente da fermentação alcoolica de batata, na produtividade de alface e na qualidade de mudas de tomateiro. Foram conduzidos a campo dois experimentos com a cultura da alface, em delineamento blocos ao acaso com três repetições, e dois experimentos em ambiente protegido com mudas de tomateiro, em bandejas de poliestireno expandido de 128 células, em delineamento inteiramente casualizado com quatro repetições. Foram avaliados a fitomassa fresca e a fitomassa seca da parte aérea da alface, a altura da planta, o diâmetro do caule, o número de folhas, a fitomassa fresca de raiz, a fitomassa fresca de parte aérea, a fitomassa seca de parte aérea e a relação entre a fitomassa fresca de parte aérea e de raiz nas mudas de tomateiro. A adubação foliar com Acrescent Foliar $^{\circledR}$ não influencia na produtividade da alface $e$ confere às mudas de tomateiro características indesejáveis como redução da fitomassa fresca de raiz e aumento da relação entre a fitomassa fresca de parte aérea e de raiz.

Palavras-chave: Solanum lycopersicum, Lactuca sativa, produção de mudas, adubação foliar, Acrescent Foliar ${ }^{\circledR}$.

\section{ABSTRACT}

The aim of this work was to evaluate the effect of application of Acrescent Foliar ${ }^{\circledR}$ derived of alcoholic fermentation of potato, in lettuce productivity and in quality of tomato seedlings. Two experiments were conducted in field with lettuce crop in a randomized block design with three replications and, two experiments were conducted in greenhouse with production of tomato seedlings in polystyrene trays with 128 cells in a complete randomized design with four replications. It was measured the fresh and dry biomass of the shoot of lettuce, and the plant height, stem diameter, number of leaves, fresh biomass of roots and shoot, dry biomass of the shoot and, the relation between the fresh biomass of shoot and roots in tomato seedlings. The foliar fertilization with Acrescent Foliar ${ }^{\circledR}$ does not influence the lettuce productivity and it conferred undesirable characteristics in the tomato seedlings such as reduced roots fresh biomass and increased ratio between the fresh biomass of shoot and roots.

Key words: Solanum lycopersicum, Lactuca sativa, Production of seedlings, Foliar fertilization, Acrescent Foliar ${ }^{\circledR}$.

\section{INTRODUÇÃO}

Alface e tomate são culturas de grande destaque na olericultura brasileira. A alface foi, em 2006, a hortaliça folhosa com maior volume de produção no Brasil (525.602 mil toneladas) (IBGE, 2006). Já o tomate, em 2011, foi a hortaliça com maior volume de produção (4.146.466 milhões de toneladas), ocupando $66.221 \mathrm{mil}$ hectares da área cultivada e com produtividade média de 62,6 toneladas por hectare (IBGE, 2012). Nesse cenário, é importante que sejam realizadas mais pesquisas com essas culturas, de modo que se obtenham resultados cada vez mais exitosos em seu cultivo.

A adubação foliar pode contribuir para a melhoria da qualidade dos produtos vegetais, complementando e corrigindo falhas da fertilização via solo, estimulando assim o desenvolvimento da cultura em determinadas fases para obter uma resposta rápida em caso de deficiências nutricionais (FILGUEIRA, 2008; LUZ et al., 2010). LUZ et al. (2010) demonstraram a viabilidade do emprego da adubação foliar com fertilizantes líquidos em

IDepartamento de Fitotecnia, Universidade Federal de Santa Maria (UFSM), 97105-900, Santa Maria, RS, Brasil. E-mail: vs.diogo@gmail.com. *Autor para correspondência. 
complemento à adubação de solo na cultura da alface, verificando aumento na produtividade.

A produção de tomate tipo mesa é realizada a partir do transplante de mudas produzidas em bandejas de poliestireno para o ambiente de produção. $\mathrm{O}$ uso de mudas de alta qualidade é fator chave no sucesso da produção comercial de hortaliças, pois existe uma relação direta entre a qualidade das mudas e a produção a campo (GUIMARÃES et al., 2002).

A adequada nutrição é fundamental para a obtenção de mudas vigorosas, com maior resistência a danos físicos e mecânicos e maior capacidade de recuperação e estabelecimento após o transplante, de modo a obter um estande de plantas homogêneo. O emprego de diversos tipos de subprodutos no condicionamento de mudas e nutrição de plantas tem sido estudado como alternativa para reduzir os custos de produção e como opção de descarte desses resíduos. $\mathrm{O}$ efeito de fertilizantes organominerais em alface (LUZ et al., 2010), águas residuárias da suinocultura e lodo têxtil em eucalipto (PELISSARI et al., 2009), biofertilizante em alface (MEDEIROS et al., 2008), águas residuárias de esgotos domésticos em eucalipto (AUGUSTO et al., 2007) e de lodo têxtil em maracujazeiro (PRADO \& NATALE, 2005) foram estudados visando ao condicionamento de mudas para posterior transplante. $\mathrm{O}$ efeito da vinhaça da cana-deaçúcar também foi avaliado sobre o desenvolvimento inicial de plantas de amendoim, girassol e mamona, com efeito positivo somente sobre o vigor inicial de mudas em formação de mamona (RAMOS et al., 2008).

Nessa linha, no ano de 2011, foi registrado, no Ministério da Agricultura, Pecuária e Abastecimento (MAPA), o produto Acrescent Foliar ${ }^{\circledR}$. Trata-se de um subproduto agroindustrial proveniente da fermentação alcoolica da batata (Solanum tuberosum L.) pela levedura Sacharomyces cerevisae. $\mathrm{O}$ bioproduto é um resíduo líquido obtido durante o processo de destilação do mosto para a produção de destilados alcoolicos. Esse produto poderia constituir uma alternativa adequada para o condicionamento de mudas de tomateiro e para a nutrição foliar da alface, pois possui similaridades com a vinhaça da canade-açúcar de alambique (OLIVEIRA et al., 2009) e de usinas sucroalcooleiras (ZOLIN et al., 2011), como acidez, potássio como nutriente em maior concentração, elevado teor de matéria orgânica e presença de outros macro e micronutrientes.

Embora alguns agricultores já estejam aplicando esse bioproduto de batata em diferentes espécies vegetais, como soja, milho, feijão e trigo, nenhum trabalho científico foi realizado até o momento para avaliar seu efeito como fertilizante foliar em hortaliças. Assim, o objetivo deste trabalho foi avaliar o efeito da aplicação foliar de bioproduto de batata na produtividade de alface e na qualidade de mudas de tomateiro.

\section{MATERIAL E MÉTODOS}

A pesquisa foi realizada na área experimental do Departamento de Fitotecnia da Universidade Federal de Santa Maria (latitude $2^{\circ} 43^{\prime}$ 'S, longitude $53^{\circ} 43^{\prime} \mathrm{W}$ e altitude $95 \mathrm{~m}$ ), no Município de Santa Maria, RS, com as culturas da alface e do tomateiro. O clima da região, segundo a classificação de Köppen (MORENO, 1961) é do tipo Cfa (subtropical úmido, sem estação seca definida e com verões quentes) e o solo classificado como Argissolo Vermelho Distrófico arênico (SISTEMA BRASILEIRO DE CLASSIFICAÇÃO DE SOLOS, 2006).

O Acrescent Foliar $^{\circledR}$, utilizado nos experimentos, foi analisado pelo Laboratório de Ecologia Florestal (LABLEFO/CCR/UFSM) e apresentou as seguintes características químicas: matéria orgânica $=24,4 \% ; \mathrm{pH}=3,2 ; \mathrm{N}=324,25 \mathrm{mg} \mathrm{L}^{-1}$; $\mathrm{P}=71,93 \mathrm{mg} \mathrm{L}^{-1} ; \mathrm{K}=465,00 \mathrm{mg} \mathrm{L}^{-1} ; \mathrm{Ca}=12,55 \mathrm{mg} \mathrm{L}^{-1}$; $\mathrm{Mg}=51,65 \mathrm{mg} \mathrm{L}^{-1} ; \mathrm{S}=39,81 \mathrm{mg} \mathrm{L}^{-1} ; \mathrm{Cu}=1,11 \mathrm{mg} \mathrm{L}^{-1}$; $\mathrm{Fe}=6,42 \mathrm{mg} \mathrm{L}^{-1} ; \mathrm{Mn}=0,42 \mathrm{mg} \mathrm{L}^{-1} ; \mathrm{Zn}=0,97 \mathrm{mg} \mathrm{L}^{-1}$.

Experimentos com alface

Foram realizados dois experimentos a campo com alface, cultivar Amanda. $\mathrm{O}$ primeiro experimento ocorreu de 18/03 a 29/04 e o segundo de 13/05 a 07/07 de 2011. As plantas foram dispostas em linhas (camalhões sem uso de mulching) espaçadas de $1,2 \mathrm{~m}$ entre linhas e $0,3 \mathrm{~m}$ entre plantas.

A adubação de transplante foi realizada com $44 \mathrm{~kg} \mathrm{ha}^{-1}$ de $\mathrm{N}, 40 \mathrm{~kg}$ ha ${ }^{-1}$ de $\mathrm{P}_{2} \mathrm{O}_{5}$ e $90 \mathrm{~kg} \mathrm{ha}^{-1}$ de $\mathrm{K}_{2} \mathrm{O}$. A adubação nitrogenada em cobertura foi realizada em três aplicações aos 15, 30 e 44 dias após o transplante (DAT), totalizando $44 \mathrm{~kg} \mathrm{ha}^{-1}$. Todas as adubações foram realizadas conforme o resultado da análise do solo (COMISSÃO DE QUÍMICA E FERTILIDADE DO SOLO RS/SC, 2004), cujos valores médios foram: $\mathrm{pH}_{\text {(água) }} 5,4$; matéria orgânica $22,5 \mathrm{mg} \mathrm{g}^{-1} ; 35 \mathrm{mg} \mathrm{dm}^{-3}$ de $\mathrm{P}$ disponível $\left(\right.$ Mehlich $^{-1}$ ); $299 \mathrm{mg} \mathrm{dm}^{-3}$ de K; 8,50 $\mathrm{cmol}_{\mathrm{c}} \mathrm{dm}^{-3}$ de Ca; 2,80 $\mathrm{cmol}_{\mathrm{c}}$ $\mathrm{dm}^{-3}$ de $\mathrm{Mg} ; \mathrm{S}=38,30 \mathrm{mg} \mathrm{dm}^{-3} ; \mathrm{Al}=0,30 \mathrm{cmol}_{\mathrm{c}} \mathrm{dm}^{-3}$; $\mathrm{H}+\mathrm{Al}=3,40 \mathrm{cmol}_{\mathrm{c}} \mathrm{dm}^{-3} ; \mathrm{Cu}=0,50 \mathrm{mg} \mathrm{dm}^{-3} ; \mathrm{Zn}=2,30 \mathrm{mg}^{-3}$ $\mathrm{dm}^{-3} ; \quad \mathrm{B}=0,40 \mathrm{mg} \mathrm{dm} \mathrm{dm}^{-3} ; \quad$ CTC $\mathrm{pH} 7=15,43 \mathrm{cmol}_{\mathrm{c}}$ $\mathrm{dm}^{-3} ; \mathrm{V}(\%)=77,20 \%$ e; argila=23,83\%. A irrigação foi realizada por gotejamento e os demais tratos culturais de acordo com a recomendação da cultura (FILGUEIRA, 2008).

No primeiro experimento, foram dispostas três linhas contendo 64 plantas cada. A parcela foi 
constituída por quatro plantas na direção da linha de cultivo. Foi utilizado o delineamento em blocos ao acaso com três repetições, em um bifatorial $(5 \times 3)$ com uma testemunha adicional (ausência de Acrescent Foliar $^{\circledR}$ ). O fator A (intervalo de aplicação foliar de Acrescent Foliar $^{\circledR}$ ) foi constituído de cinco níveis (transplante; transplante +13 dias após o transplante (DAT); transplante + 13DAT + 21DAT; 13DAT; e 21DAT). O fator D (doses de Acrescent Foliar ${ }^{\circledR}$ ) foi constituído por três níveis $\left(2,75 ; 5,5\right.$; e $\left.8,25 \mathrm{~L} \mathrm{ha}^{-1}\right)$.

No segundo experimento, foram dispostas três linhas contendo 60 plantas cada. A parcela foi constituída por duas plantas na direção da linha de cultivo. Foi utilizado o delineamento em blocos ao acaso com três repetições, unifatorial, sendo os tratamentos a combinação dos intervalos de aplicação foliar de Acrescent Foliar ${ }^{\circledR}$ (pegamento das mudas + aplicações em intervalos de sete dias; pegamento das mudas + aplicações em intervalos de 10 dias) com doses de Acrescent Foliar ${ }^{\circledR}(2 ; 4 ; 6 ; 8 ; 10 ; 12 ;$ e 14L ha $^{-1}$ ), mais o tratamento com ausência de Acrescent Foliar $^{\circledR}$ (testemunha). Todas as aplicações foram realizadas com borrifadores, diluindo-se as doses do produto em $20 \mathrm{~mL}$ de água por parcela.

A fitomassa fresca da parte aérea foi determinada em balança digital. Em seguida, cada planta foi seca em estufa de circulação de ar até massa constante, determinando-se a fitomassa seca da parte aérea.

No primeiro experimento, realizou-se a análise de variância pelo modelo matemático do delineamento em blocos ao acaso em um bifatorial com a presença de uma testemunha adicional (GOMES \& GARCIA, 2002), determinando o efeito das doses de Acrescent Foliar ${ }^{\circledR}$ pela análise de regressão e comparando os tratamentos com e sem Acrescent Foliar ${ }^{\circledR}$ pelo teste de Scheffé balanceado. No segundo experimento, realizou-se a análise de variância unifatorial, considerando o delineamento em blocos ao acaso com repetição dentro do bloco (BANZATTO \& KRONKA, 2006), comparando os tratamentos pelo teste de Scheffé balanceado.

Experimentos com tomateiro

Para a cultura do tomateiro, foram realizados dois experimentos com formação de mudas em bandejas de poliestireno expandido de 128 células, preenchidas com o substrato Mecplant ${ }^{\circledR}$ no período de 15/03 a 19/04 (1º experimento) e 27/04 a 17/06/2011 (2o experimento). O subtrato utilizado é composto de casca de pinus bio-estabilizada, corretivo de acidez e fertilizantes minerais, com capacidade de retenção de água de $60 \%$ em massa, capacidade de troca de cátions de $200 \mathrm{mmol} \mathrm{kg}^{-1}$ e umidade em massa de $60 \%$. Foi utilizada a variedade Coração de boi, sendo o primeiro experimento mantido em túnel plástico e o segundo em casa de vegetação, ambos sobre bancadas.

Foram realizadas adubações semanais via água de irrigação, utilizando a fórmula 13-40$13\left(\mathrm{~N}-\mathrm{P}_{2} \mathrm{O}_{5}-\mathrm{K}_{2} \mathrm{O}\right)$, e após as mudas atingirem quatro folhas utilizando a fórmula 18-18-18 $\left(\mathrm{N}-\mathrm{P}_{2} \mathrm{O}_{5}-\mathrm{K}_{2} \mathrm{O}\right)$. A diluição em água foi na dose de $2,5 \mathrm{~g}$ de adubo $\mathrm{Lm}^{-2}$. A irrigação foi realizada de acordo com a necessidade das mudas e utilizando regador.

Foi empregado odelineamentointeiramente casualizado, com quatro repetições. Cada bandeja recebeu três tratamentos, que foram constituídos por 32 células, deixando-se duas fileiras sem plantas, de modo a evitar a competição interparcelar. Visando a reduzir influências locais, as bandejas foram trocadas de lugar duas vezes por semana.

Os tratamentos estudados nos dois experimentos foram seis doses de Acrescent Foliar ${ }^{\circledR}$, diluídas em água e aplicadas com borrifador sobre a parte aérea (folhas e caule) e substrato. No primeiro experimento, foram avaliadas as doses 0, 60, 120, 180, 240 e 300mL de Acrescent Foliar ${ }^{\circledR}$ por bandeja. Essas aplicações foram realizadas aos 7, 14 e 21 dias após a emergência das plantas (DAE) e diluídas em $75 \mathrm{~mL}$ de água. No segundo experimento, foram avaliadas as doses $0,35,70,105,140$ e $175 \mathrm{~mL}$ de Acrescent Foliar ${ }^{\circledR}$ por bandeja aos 7, 14, 21 e 28DAE, diluídas em 50mL de água.

Avaliaram-se, de forma aleatória, 15 e 14 plantas por parcela, respectivamente, no primeiro e no segundo experimento, quando estas apresentavam 4 a 5 folhas. As variáveis analisadas foram: altura da planta; diâmetro do caule logo acima do colo da planta; número de folhas; fitomassa fresca de raiz e fitomassa fresca de parte aérea; fitomassa seca de parte aérea, obtida após secagem em estufa de circulação de ar até massa constante; e relação entre a fitomassa fresca de parte aérea e de raiz.

Nos dois experimentos, a análise de variância foi realizada pelo modelo matemático do delineamento inteiramente casualizado com amostragem na parcela. $\mathrm{O}$ efeito dos tratamentos foi determinado pela análise de regressão.

Anteriormente à análise de variância, os dados de todos os experimentos foram submetidos aos testes dos pressupostos do modelo matemático. Todas as análises estatísticas foram realizadas em nível de 5\% de probabilidade de erro com o pacote estatístico SOCNTIA(EMBRAPA, 1997) e o aplicativo Office Excel ${ }^{\circledR}$.

Ciência Rural, v.43, n.3, mar, 2013. 


\section{RESULTADOS E DISCUSSÃO}

Experimentos com alface

No primeiro experimento com alface, não houve interação entre o intervalo de aplicação e as doses de Acrescent Foliar $^{\circledR}$ aplicadas em complementação à adubação mineral. Também não houve efeito principal do intervalo de aplicação (fator qualitativo) pela análise de variância, e das doses de Acrescent Foliar $^{\circledR}$ (fator quantitativo) pela análise de regressão, nem diferença entre a testemunha sem Acrescent Foliar ${ }^{\circledR}$ e os tratamentos com Acrescent Foliar ${ }^{\circledR}$ para a fitomassa fresca e seca da parte aérea (Tabela 1). No segundo experimento, as doses e intervalos de aplicação de Acrescent Foliar $^{\circledR}$, comparadas pelo teste de Sheffé, também não influenciaram na fitomassa fresca e seca da parte aérea, não havendo diferença entre a testemunha sem Acrescent Foliar $^{\circledR}$ e os tratamentos com Acrescent Foliar $^{\circledR}$ (Tabela 1). Esses resultados são contrários aos obtidos por LUZ et al. (2010), que observaram incremento da produtividade da alface com adubação foliar por diferentes fertilizantes organominerais em complemento à adubação mineral de solo.

O alto nível de fertilidade do solo, associado à adubação de solo realizada de modo integral e as baixas doses de bioproduto da batata aplicadas podem ser as responsáveis pela ausência de influência desse produto sobre a produtividade da alface, já que a COMISSÃO DE QUÍMICA E FERTILIDADE DO SOLO RS/SC (2004) preconiza que, quando os teores de nutrientes no solo estão acima do nível crítico, a probabilidade de resposta das culturas à adição de fertilizantes é baixa ou mesmo nula. Novos estudos devem ser realizados visando à substituição de parte da adubação mineral via solo pelo Acrescent Foliar ${ }^{\circledR}$, emprego de doses mais elevadas, culturas com maiores exigências nutricionais e análise quantitativa dos teores foliares de nutrientes.

\section{Experimentos com tomateiro}

No primeiro experimento com produção de mudas de tomateiro, as doses de 240 e $300 \mathrm{~mL}$ de Acrescent Foliar ${ }^{\circledR}$ por bandeja, equivalentes a 10.381

Tabela 1 - Teste de Scheffé para as varíaveis fitomassa fresca (FMF, g) e fitomassa seca (FMS, g) de parte aérea de alface cultivada com Acrescent Foliar ${ }^{\circledR}$. Santa Maria, UFSM, 2011.

\begin{tabular}{|c|c|c|}
\hline \multirow{2}{*}{ Contrastes } & & \multirow[b]{2}{*}{ FMS } \\
\hline & FMF & \\
\hline \multicolumn{3}{|c|}{ 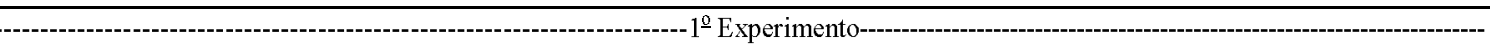 } \\
\hline Sem Acrescent Foliar ${ }^{\mathbb{R}}$ vs. Com Acrescent Foliar ${ }^{\mathbb{R}}$ & $-524,25^{\text {ns }}$ & $2,00^{\mathrm{ns}}$ \\
\hline Média & 292,37 & 17,39 \\
\hline $\mathrm{CV}(\%)$ & 15,11 & 13,48 \\
\hline \multicolumn{2}{|c|}{$-2^{\underline{Q}}$ Experimento--.-.-. } & $-35,19^{\text {ns }}$ \\
\hline $\mathrm{X}_{1}$ & $-0,72^{\text {ns }}$ & $-0,91^{\mathrm{ns}}$ \\
\hline $\mathrm{x}_{2}$ & $2,08^{\text {ns }}$ & $0,32^{\mathrm{ns}}$ \\
\hline$x_{3}$ & $8,78^{\text {ns }}$ & $1,02^{\text {ns }}$ \\
\hline$x_{4}$ & $-211,33^{\mathrm{ns}}$ & $-17,14^{\mathrm{ns}}$ \\
\hline $\mathrm{X}_{5}$ & $-212,05^{\text {ns }}$ & $-18,05^{\text {ns }}$ \\
\hline $\mathrm{X}_{6}$ & $-3,75^{\text {ns }}$ & $-2,13^{\text {ns }}$ \\
\hline $\mathrm{X}_{7}$ & $2,95^{\mathrm{ns}}$ & $-1,42^{\text {ns }}$ \\
\hline $\mathrm{X}_{8}$ & $5,03^{\text {ns }}$ & $-1,10^{\mathrm{ns}}$ \\
\hline $\mathrm{X}_{9}$ & $5,83^{\text {ns }}$ & $2,44^{\mathrm{ns}}$ \\
\hline Média & 152,14 & 14,07 \\
\hline $\mathrm{CV}(\%)$ & 18,16 & 16,16 \\
\hline
\end{tabular}

$\mathrm{X}_{1}=$ Acrescent Foliar ${ }^{\circledR} 7 \mathrm{em} 7$ dias vs. Acrescent Foliar ${ }^{\circledR} 10 \mathrm{em} 10$ dias: $\mathrm{X}_{2}=$ Acrescent Foliar ${ }^{\circledR} 7 \mathrm{em} 7$ dias dose baixa vs. Acrescent Foliar ${ }^{\circledR}$ dose alta; $\mathrm{X}_{3}=$ Acrescent Foliar ${ }^{\mathbb{B}} 10 \mathrm{em} 10$ dias dose baixa vs. Acrescent Foliar ${ }^{\mathbb{R}}$ dose alta; $\mathrm{X}_{4}=$ Sem Acrescent Foliar ${ }^{\mathbb{B}}$ vs. com Acrescent Foliar $^{\mathbb{R}} 7 \mathrm{em} 7$ dias; $\mathrm{X}_{5}-$ Sem Acrescent Foliar ${ }^{\mathbb{E}}$ vs. com Acrescent Foliar ${ }^{\mathbb{R}} 10 \mathrm{em} 10$ dias; $\mathrm{X}_{6}=$ Acrescent Foliar ${ }^{\mathbb{R}} 7 \mathrm{em} 7$ dias dose baixa vs. Acrescent Foliar ${ }^{\mathbb{B}} 10 \mathrm{em} 10$ dias; $\mathrm{X}_{7}=$ Acrescent Foliar ${ }^{\mathbb{B}} 7 \mathrm{em} 7$ dias dose alta vs. Acrescent Foliar ${ }^{\mathbb{B}} 10 \mathrm{em} 10$ dias dose alta; $\mathrm{X}_{8}=$ Acrescent Foliar $^{\mathbb{R}} 7 \mathrm{em} 7$ dias dose baixa vs. Acrescent Foliar ${ }^{\mathbb{R}} 10 \mathrm{em} 10$ dias dose alta; $\mathrm{X}_{9}=$ Acrescent Foliar ${ }^{\mathbb{R}} 10 \mathrm{em} 10$ dias dose baixa vs. Acrescent Foliar $^{\mathbb{B}} 7 \mathrm{em} 7$ dias dose alta. Dose baixa $=\left(2,4 \mathrm{e} 6 \mathrm{~L} \mathrm{ha}^{-1}\right.$ de Acrescent Foliar $\left.{ }^{\mathbb{B}}\right)$; Dose alta $=\left(10,12 \mathrm{e} 14 \mathrm{~L} \mathrm{ha}{ }^{-1}\right.$ de Acrescent Foliar $\left.{ }^{\mathbb{B}}\right)$. CV $(\%)$ - coeficiente de variação. 
e 12.976L ha-1, provocaram a morte das mudas em formação (Figura 1Aaté 1G). Mudas de maracujazeiro também morreram em doses de lodo têxtil maiores que $10 \mathrm{Mg} \mathrm{ha}^{-1}$ (PRADO \& NATALE, 2005), e a aplicação de $150 \mathrm{~m}^{3} \mathrm{ha}^{-1}$ de vinhaça de cana-de-açúcar foi prejudicial à germinação e ao desenvolvimento

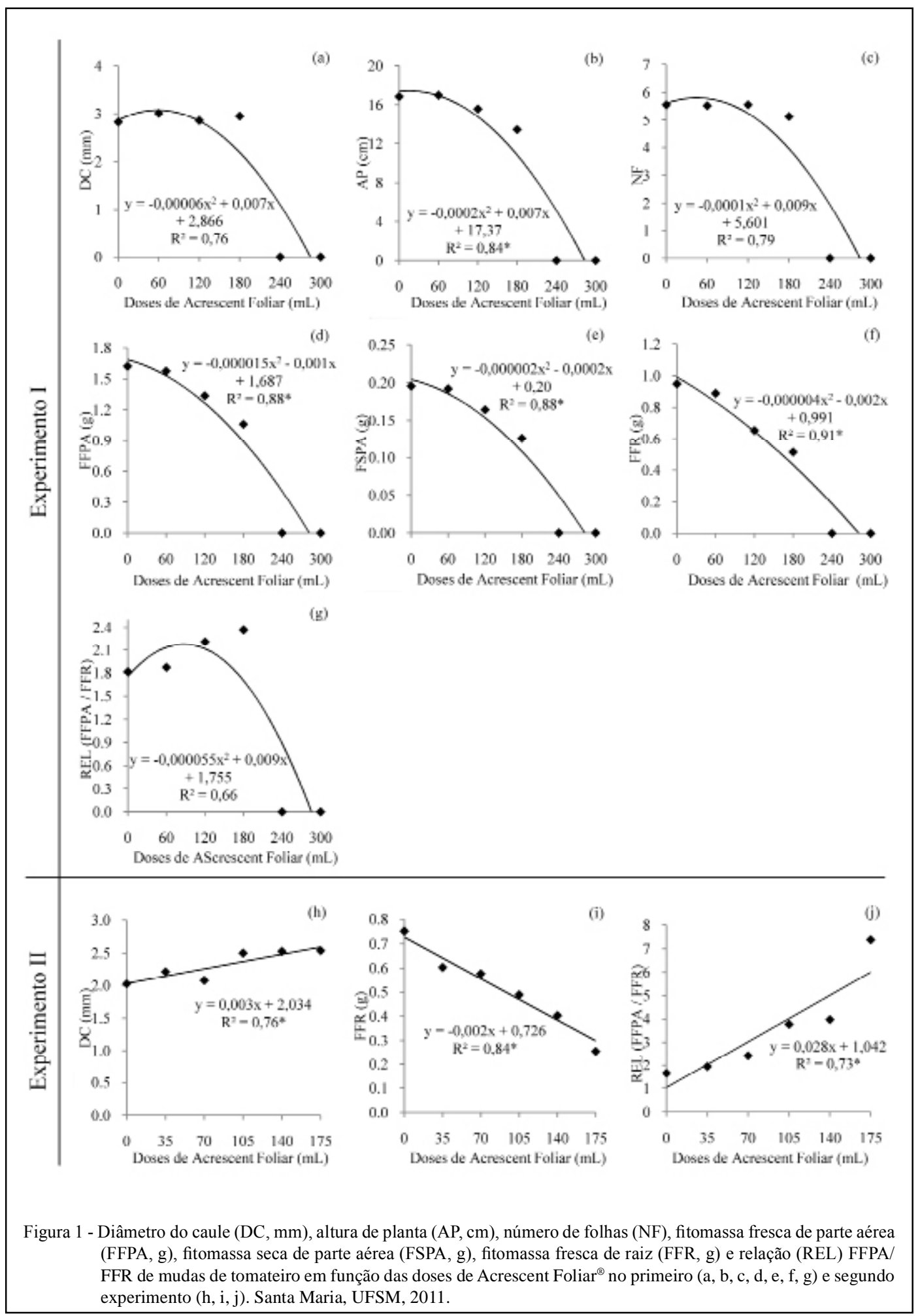

Ciência Rural, v.43, n.3, mar, 2013. 
inicial de mudas de girassol e de amendoim (RAMOS et al., 2008). Por outro lado, mudas de eucalipto cresceram sem deficiência ou toxidez aparente, sob aplicação exclusiva de água residuária de esgoto doméstico na irrigação (AUGUSTO et al., 2007).

Ainda no primeiro experimento, todas as variáveis morfológicas apresentaram comportamento quadrático decrescente, indicando ação inibitória do bioproduto de batata sobre o desenvolvimento inicial das mudas de tomate (Figura 1A até $1 \mathrm{G}$ ), efeito similar ao da vinhaça de cana-de-açúcar, observado por RAMOS et al. (2008), sobre mudas de girassol e amendoim. Em virtude da possibilidade das curvas de regressão terem sido influenciadas pelos valores zero, decorrentes da morte das mudas em formação, o segundo experimento foi instalado utilizando como limite superior a dose de $180 \mathrm{~mL}$ de bioproduto por bandeja $\left(7.785 \mathrm{~L} \mathrm{ha}^{-1}\right)$, que não causou a morte das mudas (Figura 1).

Os resultados do segundo experimento mostram comportamento linear crescente do diâmetro do caule (DC), em função do aumento da dose de Acrescent Foliar $^{\circledR}$ (Figura $1 \mathrm{H}$ ), característica que pode conferir às mudas maior tolerância a estresses mecânicos, como vento e precipitação após o transplante. Porém, o comportamento linear decrescente da fitomassa fresca de raiz (FFR) e linear crescente da relação entre a fitomassa fresca da parte aérea e a fitomassa fresca de raiz (REL) (Figuras 1I e 1J) confirmaram os efeitos negativos do bioproduto sobre as mudas em formação, também observado no primeiro experimento nas mesmas variáveis (Figuras $1 \mathrm{~F} \mathrm{e} \mathrm{1G).}$

Mudas com maior REL são totalmente indesejáveis para o transplante, pois estarão mais sujeitas à morte por desidratação, em virtude da maior aérea foliar exposta à radiação solar e ao vento, e ao pequeno volume radicular para a absorção de água e nutrientes, resultando em menores taxas de pegamento, desenvolvimento inicial lento, maior necessidade de replantio e maiores custos de produção (MARQUES et al. 2003). Por outro lado, AUGUSTO et al. (2007) verificaram incremento na relação raiz/parte aérea em mudas de eucalipto produzidas exclusivamente com água residuária de esgoto doméstico. Além disso, PELISSARI et al. (2009) também observaram efeito favorável do uso de água residuária da suinocultura sobre o diâmetro do caule e altura de mudas em eucalipto.

Possivelmente, os ácidos orgânicos responsáveis pelo baixo $\mathrm{pH}$ do Acrescent Foliar ${ }^{\circledR}$, a concentração de potássio e a sensibilidade das mudas de tomateiro sejam explicações para a morte e os efeitos negativos observados nas mudas em formação após a aplicação do bioproduto. A elevação do potencial osmótico do substrato pela aplicação do bioproduto pode ter dificultado a extração de água e nutrientes pelas raízes, assim como solutos podem ter causado efeitos tóxicos à cultura (RAMOS et al., 2008). Conforme PRADO \& NATALE (2005), altos teores de potássio, por seu efeito salino, inibem o crescimento radicular das mudas, que perdem sua capacidade de absorção de água e nutrientes, o que resulta também em redução dos demais parâmetros de qualidade. Por outro lado, RAMOS et al. (2008) verificaram efeito positivo da aplicação de $150 \mathrm{~m}^{3}$ $\mathrm{ha}^{-1}$ da vinhaça da cana-de-açúcar no vigor inicial de mudas de mamona, indicando que o comportamento é influenciado pela espécie estudada. Novos estudos devem abranger todo o ciclo da cultura do tomateiro para verificar o comportamento das mudas a campo e a produtividade, além de estender as pesquisas a outras hortaliças.

\section{CONCLUSÃO}

A adubação foliar com Acrescent Foliar $^{\circledR}$ não influencia na produtividade da alface e confere às mudas de tomateiro em formação características indesejáveis, como redução da fitomassa fresca de raiz e aumento da relação entre a fitomassa fresca de parte aérea e de raiz.

\section{AGRADECIMENTOS}

À Santa Eulália Indústria de Bebidas e Fertilizantes LTDA, pelo produto Acrescent Foliar ${ }^{\circledR}$.

\section{REFERÊNCIAS}

AUGUSTO, D.C.C. et al. Utilização de águas residuárias provenientes do tratamento biológico de esgotos domésticos na produção de mudas de Eucalyptus grandis Hill. ex.Maiden. Revista Árvore, v.31, n.4, p.745-751, 2007. Disponível em: <http://www.scielo.br/pdf/rarv/v31n4/20.pdf >. Acesso em: 5 jul. 2011. doi: 10.1590/S0100-67622007000400020.

BANZATTO, D.A.; KRONKA, S.N. Experimentação agrícola. 4.ed. São Paulo: FUNEP, 2006. 237p.

COMISSÃO DE QUÍMICA E FERTILIDADE DO SOLO RS/ $\mathrm{SC}$ (CQFS-RS/SC). Manual de adubação e de calagem para o Estado do Rio Grande do Sul e Santa Catarina. Porto Alegre: UFRGS, 2004. 400p.

EMBRAPA. Ambiente de software NTIA, versão 4.2.2: manual do usuário - ferramental estatístico. Campinas: Centro Nacional de Pesquisa Tecnológica em Informática para a Agricultura, 1997. 258p.

FILGUEIRA, F.A.R. Novo manual de olericultura: agrotecnologia moderna na produção e comercialização de hortaliças. Viçosa: UFV, 2008. 421p. 
GOMES, F.P.; GARCIA, C.H. Estatística aplicada a experimentos agronômicos e florestais: exposição com exemplo e orientações para uso e aplicativos. Viçosa: FEALQ, 2002. 309p.

GUIMARÃES, V.F. et al. Métodos de produção de mudas, distribuição de matéria seca e produtividade de plantas beterraba. Horticultura Brasileira, v.20, n.3, p.505-509, 2002. Disponível em: <http://www.scielo.br/scielo.php?script=sci_ arttext\&pid=S0102-05362002000300022\&lng=pt\&nrm =iso \&tlng=pt $>$. Acesso em: 17 set. 2011. doi: 10.1590/S010205362002000300022 .

IBGE. Censo Agropecuário, 2006. Disponível em: <http://www. cnph.embrapa.br/paginas/hortalicas_em_numeros/hortalicas_em_ numeros.htm>. Acesso em: 17 set. 2011.

IBGE. Levantamento sistemático da produção agrícola. Disponível em: <http://www.ibge.gov.br/home/estatistica/ indicadores/agropecuaria/lspa/lspa_201202.pdf >. Acesso em: 23 jul. 2012.

LUZ, J.M.Q. et al. Aplicação foliar de fertilizantes organominerais em cultura de alface. Horticultura Brasileira, v.28 n.3, p.373377, 2010. Disponível em: <http://www.abhorticultura.com.br/ Revista/revista/PH_1936.pdf>. Acesso em: 18 set. 2011. doi: 10.1590/S0102-05362010000300023.

MARQUES, P.A.A. et al. Qualidade de mudas de alface formadas em bandejas de isopor com diferentes números de células. Horticultura Brasileira, v.21, n.4, p.649-651, 2003. Disponível em: 〈http://www.scielo.br/pdf/hb/v21n4/19431.pdf>. Acesso em: 19 set. 2011. doi: 10.1590/S0102-05362003000400015.

MEDEIROS, D.C. de. et al. Qualidade de mudas de alface em função de substratos com e sem biofertilizante. Horticultura Brasileira, v.26, n.2, p.186-189, 2008. Disponível em: <http:// www.scielo.br/pdf/hb/v26n2/11.pdf >. Acesso em: 5 jul. 2011. doi: 10.1590/S0102-05362008000200011.
MORENO, J.A. Clima no Rio Grande do Sul. Porto Alegre: Secretaria da Agricultura, 1961. 41p.

OLIVEIRA, E.L. et al. Uso de vinhaça de alambique e nitrogênio em cana-de-açúcar irrigada e não irrigada. Pesquisa Agropecuária Brasileira, v.44, n.11, p.1398-1403, 2009. Disponível em: <http:// www.scielo.br/pdf/pab/v44n11/05.pdf>. Acesso em: 10 set. 2011. doi: 10.1590/S0100-204X2009001100005.

PELISSARI, R.A.Z.et al. Lodo têxtil e água residuária da suinocultura na produção de mudas de Eucalyptus grandis (W, Hill exMaiden). Engenharia Agrícola, v.29, n.2, p.288-300, 2009. Disponível em: 〈www.scielo.br/pdf/eagri/v29n2/12.pdf〉. Acesso em: 18 set. 2011. doi: 10.1590/S0100-69162009000200012.

PRADO, R.M.; NATALE, W. Desenvolvimento inicial e estado nutricional do maracujazeiro em resposta à aplicação de lodo têxtil. Pesquisa Agropecuária Brasileira, v.40, n.6, p.621-626, 2005. Disponível em: <http://http://webnotes.sct.embrapa.br/pdf/ pab2005/junho/40n06a15.pdf>. Aceso em: 17 set. 2011. doi: 10.1590/S0100-204X2005000600015.

RAMOS, N.P. et al. Efeito da vinhaça no desenvolvimento inicial de girassol, mamona e amendoim em casa de vegetação. Bragantia, v.67, n.3, p.685-692, 2008. Disponível em: <http:// www.scielo.br/pdf/brag/v67n3/a17v67n3.pdf>. Acesso em: 5 jul. 2011.

SISTEMA BRASILEIRO DE CLASSIFICAÇÃO DE SOLOS. Rio de Janeiro: Embrapa Solos, 2006. 306p.

ZOLIN, C.A. et al. Estudo exploratório do uso da vinhaça ao longo do tempo: I. Características do solo. Revista Brasileira de Engenharia Agrícola e Ambiental, v.15, n.1, p.22-28, 2011. Disponível em:<http://www.scielo.br/pdf/rbeaa/v15n1/ a04v15n01.pdf>. Acesso em: 10 set. 2011. doi: 10.1590/S141543662011000100004.

Ciência Rural, v.43, n.3, mar, 2013. 